\title{
Research on Stimulus Meaning and Symbols
}

\author{
Gao Yang
}

School of Philosophy, Political Science and Law, Yunnan Normal University, Yunnan, Kunming 650500

Keywords: meaning; stimulation; behavior; symbol

\begin{abstract}
Quine's stimulating meaning theory can be described as unique in the theory of various meanings after the turn of language. Its uniqueness lies in the emphasis on the sociality of language and the emphasis on behavior. From Quine's naturalistic standpoint, he conceived two typical scenes of children's language learning and linguists' translation of strange language. These two scenes highlight their naturalistic position. In the question of how to determine the consistency of stimuli meaning, Quine and his student Davidson proposed the idea of "triangulation" to explain, and the translation of strange language became an example of applying this strategy. The acquisition of stimulating meaning is related to the symbolization of human beings, whether it is objects or behaviors that are understood as symbols, and the idea of "triangulation" is easily associated with Pierce's "symbolic triangle" theory. An attempt to explain Quine's stimulating meaning theory with Pierce's semiotic thinking not only expanded the theoretical perspective of meaning exploration, but also fundamentally treated language as a symbol, which enabled him to gain new insights into the meaning issue. Breakthrough.
\end{abstract}

In the tide of analytic philosophy, the American philosopher WV Quine's practice of turning meaning into the external behavior of people and transforming meaning into "stimulating meaning" can be described as a sharp alienation, but starting from Frege's From the perspective of psychologism, it can be said that it can be said that it is similar to the others. In the various tasks after the turn of language, the question of what is the meaning is the question that must be faced and solved in the analytical philosophy that this is the core research object.

\section{The Analysis of Stimuli}

The heritage left by modern philosophy for later generations has left a few regrets, whether it is Descartes' "clear, unquestionable" or Locke's "concept." Historically, the establishment and understanding of subjectivity will experience other similar processes even if they do not experience a "Cartesian-Kantian" line, because if even the concept of subjectivity cannot be established, philosophers will not need to worry about discussing language and meaning issues. The achievements highlighted by this process and the critical point of being criticized all point to the subjectivity of people. People use their unique ways to understand the world, others and themselves. However, from the individual person who is the subject of the awareness activity to the whole body, from the individual experience to the entire body of knowledge, there is a striking and unanimous agreement. To explain this phenomenon, if it is not through simple metaphysical presuppositions or even God's help, it must use complex thinking operations to create the transfer of the individual form of thinking to the whole to ensure that the experience and knowledge on the basis of the same, from Descartes' "gift concept" to Kant's "transcendental philosophy" just shows the efforts of modern philosophers. Modern philosophers may have seen new ways of explanation. Frege and Husserl raised the banner against psychologicalism at about the same time. Psychology has also become the "public enemy" of the philosophers of that era. It is only opposed. There are differences in ways and paths. Due to the opening of his representative book, "Language and Object," Xu Yan stated that "Language is a social skill." [Quine, W. V. Word and Object. Cambridge: The M.I.T. Press, 1960. p. 1] At least in Quine's view, the intersubjective transformation and substitution of subjectivity is successful in the explanation of the meaning issue. This basic attitude, coupled with its unique naturalist position formed after embedding empiricism, scientism, and behaviorism, has 
produced his own unique anti-psychopolitical tactics-using stimuli to transform traditional concepts of meaning. And use it instead.

\section{Behavior as a Symbol}

Why should we choose a behaviorist stance and why should we use stimulus as a reference to meaning? Quine's student and Quine’s research expert D. Følledal believe that from the source and basic standpoint: "Quine's behaviorism originates from its empiricism, that is, all knowledge about our world and others needs to be presented to us through the senses." [Føllesdal, Dagfinn. "Developments in Quine's Behaviorism." American Philosophical Quarterly 48, no. 3 (2011): 273-82. p. 273] From the perspective of human cognition and language look, "The reason to be a behaviorist is that when we try to understand certain social phenomena, such as the learning and use of language, we must focus on the evidence that participants get in the corresponding social situations.... All of the things acquired through the sensory channels are not all available in normal public communication.” [Ibid., p. 274] Combining the emphasis on the social aspects of Quine, his theoretical approach to behavioralism is not difficult to understand.

How to stimulate the externalization of human behavior into a medium that can be publicly observed and identified. On this issue, Quine showed us two typical scenarios. One is to learn the first sentences of the aforementioned children. One of the processes is the translation process in the face of unfamiliar languages. These two conditions obviously cannot be considered to be universally considered to include all human cognitive and language activities, but they are the two most important ones.He believes that "the way different people grow in the same language environment is like different shrubs that are pruned and cultivated into exactly the same shape of an elephant. The specific shapes of branches and leaves of different shrubs make the way the elephant is constructed unique. However the result of the last two is nearly the same. Therefore, when we consider from the behavioral characteristics and lifestyle of humanity as a whole, it seems plausible.Butfor the differences at the individual levelinthis process, Que causes the concept of "collateral information" to illustrate, and thus has a compositional theory.

\section{Triangulation and Symbol Triangle}

D. Davidson, Quine's outstanding student, also is intended to solve this problem. He thought: "Language experts try to make a representation of what is valid for someone who speaks another language. As far as possible, people who hold another language think that the statement that is true (or false) is mapped to a statement that the linguist believes to be true (or false)." The principle of charity is proposed to maximize the assumingthat indigenous peoples and linguists agree on all basic matters and minimize the gap between the two understandings, in order to ensure that the appearance of visual stimuli in rabbits is similar, translation can only be performed. Another thought of Davidson inspired the cause of Quine's thinking on the meaning problem. Quine had mentioned the idea of a triangular model in his later years' essay. This idea came from Davidson's "occasionally mentioned" one. Inspired by the idea of triangulation, putting the "triangulation" model into consideration in Pierce's semiotic vision will appear to be a useful attempt for the author as a posterior because the image, voice, and language of the rabbit is all understood as symbols. Distinct from the expansion of the scope of the theory, the investigation has a broader space. As showed in Figure 2, compared with the semiotic structure of another founder, Saussure, who prefers a binary structure, Pierce always adheres to the ternary relationship. The three vertices of the triangle are the representation, the interpretation, and the object. The "object" corner is equal to the one in triangulation. The positions of "you" and "me" in the latter are replaced with the reproduction and interpretation items. In gavage's thought experiment, from the perspective of linguists, "you" refers to indigenous people, "I" refers to linguists, and "objects" are observed by two people at the same time. The rabbit arrived; in the "symbol triangle", the reproduction body became the voice of the savage that the indigenous people shouted, and the interpretation item was the linguist's understanding of this voice symbol, and the object was still in the rabbit. 


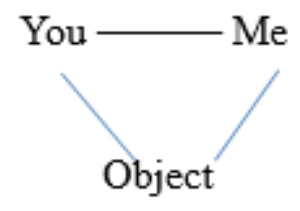

Figure 1. D. Davidson’s “triangulation”

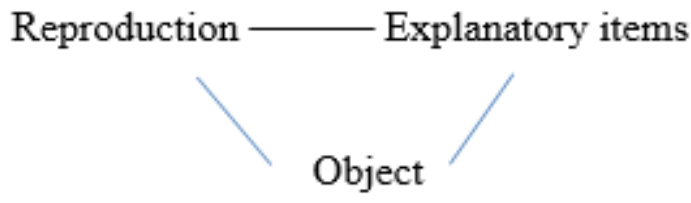

Figure 2:"Pierce" symbol triangle

How Pierce's symbolic trigonometry fits "triangulation" and interprets stimuli in new ways is an important reason why stimuli and behavior are transmitted in a symbolic way to the current single subject and between the subjects.In the process of translation, some of the issues that arise can also be explained in the semiotic vision.

\section{Conclusion}

The acquisition of meaning is linked to the characteristics and use of language. It is also associated with the success of human cognitive activities. Looking at Quine's theory of meaning and naturalized epistemology, the naturalization of meaning - turning meaning into stimulating meaning is both a prerequisite for the naturalization of epistemology and an important part of this process. As Lager said: "Quine believes that without the help of philosophy or other suspicious ideas (especially meanings and propositions), it is still possible to explain how a plan is learned, that is, how scientific theories are established. This is the principal work he has been focusing on for almost 40 years." The purpose of this work is to "reconstruct rationally how an individual or a race actually gets a reliable theory of the external world." That is the way to realize from stimulus to science transition. Peirce's "symbolic triangle" theory is to examine Quine's stimulating significant theory can be regarded as a beneficial attempt. From the side, it also illustrates the view of language as a unique symbol system of human beings. At the same time, human symbolization of objects makes them objects. Symbols also play a fundamental role in the operation of human thinking. Theoretical assumptions about this role have produced research on mentalese, and there are more and more natural science disciplines such as brain science and neuroscience are involved. From this perspective, it is consistent with Quin's naturalist stance that includes empiricism and scientism. From Quine's and Davidson's triangulation thoughts to Pierce's symbolic triangle thoughts, it shows a process from language return to a more original stimulus to return to the extension of the territory to which the language belongs. The language is ultimately a representational system. It is likewise essentially a symbol. Therefore, when the problem of meaning that has been receiving much attention since the change of language has been transferred to the field of semiotics, this problem cannot only be reasonably explained, but also has sufficient reason to believe it can be brand new. The way was resolved.

\section{References}

[1] ZhaoYiheng. Semiotics: Principles and Deduction [M]. Nanjing: Nanjing University Press.

[2] FøLoudly, Dagfinn. "Developments in Quine're Behaviorism." American Philosophical Quarterly 48, no. 3 (2011): 273-82.

[3] Davidson, Donald. "Truth and Meaning." Synthese 17, no. 3 (1967): 304-23.

[4] [Canada] By A. Lager, Translated byLi Puqun. Wittgenstein and Quinn: Two Philosophies that Are Compatible and Not Opposing [J]. World Philosophy, 2016: (3).

[5] [United States] By Li Sika, Translated by Zhao Xingzhi. Introduction to Pierce Semiotics [M]. Chengdu: Sichuan University Press, 2014. 